\title{
GAMBARAN KUALITAS TIDUR PADA PENDERITA HIPERTENSI QUALITY OF SLEEP AMONG HYPERTENSION PATIENTS
}

\author{
Putwi Rizki Sakinah', Cecep Eli Kosasih², Eka Afrima Sari ${ }^{3}$ \\ 1,2,3Fakultas Keperawatan Universitas Padjadjaran \\ ${ }^{*}$ Corresponding author: Cecep Eli Kosasih Fakultas Keperawatan Universitas Padjadjaran \\ Tlp: +6281320941727, Email: cecep.e.kosasih@unpad.ac.id
}

\begin{abstract}
People with hypertension experience symptoms of dizziness, headache, obstructive sleep apnea, shortness of breath, nocturia, and restless legs syndrome which disturb sleep and reduce its quality. This research's objective was to describe the sleep quality overview of Puskesmas Rancaekek's hypertension patients. Using descriptive quantitative method with purposive sampling technique, this research aimed at 79 Puskesmas Rancaekek's patients who had been diagnosed with hypertension for at least one month long. The data were collected using the Pittsburgh Sleep Quality Index (PSQI) questionnaire and analysed using the total score resulted; $\leq 5$ was good while $>5$ was poor. Results showed $94.6 \%$ of respondents had poor sleep quality. The dimensions that contribute to the poor sleep quality included $>30$ minutes sleep latency, $<5$ hours sleep duration, $<65 \%$ of sleep efficiency, sleep disturbance due to waking up at midnight or early morning and waking up to toilet, and activity disturbance at daylight. The conclusion was that Puskesmas need to develop preventive and promotive efforts to minimize the complication of hypertension patients and optimize their quality of life by helping them improve their quality of sleep. Meanwhile, the self-management that should be done by the patients were avoiding the consumption of coffee and cigarettes, limiting physical activities, and doing physical exercise and relaxation therapies.
\end{abstract}

Key Words: Hypertension, Sleep Quality, PSQI

\section{Abstrak}

Penderita hipertensi mengalami gejala pusing, nyeri kepala, obstructive sleep apnea, sesak napas, nokturia, restless legs syndrome yang mengganggu tidur dan berdampak pada kualitas tidur serta mempengaruhi kualitas hidup dan tekanan darah. Penelitian bertujuan untuk melihat gambaran kualitas tidur pada penderita hipertensi di Puskesmas Rancaekek. Metode penelitian menggunakan deskriptif kuantitatif dengan teknik purposive sampling sebanyak 79 penderita hipertensi di Puskesmas Rancaekek yang telah didiagnosis dokter minimal 1 bulan. Pengambilan data menggunakan kuesioner Pittsburgh Sleep Quality Index (PSQI) dan dianalisis menggunakan total skor, jika skor $\leq 5$ baik dan skor $>5$ buruk. Hasil menunjukan 94,6\% responden memiliki kualitas tidur buruk. Dimensi yang berkontribusi terhadap kualitas tidur buruk yaitu latensi tidur tidak dapat tertidur dalam waktu 30 menit, durasi tidur $<5$ jam, efisiensi kebiasaan tidur $<65 \%$, gangguan tidur karena terbangun tengah malam atau pagi sekali dan terbangun karena ingin ke toilet, serta gangguan aktivitas pada siang hari. Puskesmas perlu mengembangkan upaya preventif dan promotif untuk meminimalisir komplikasi penderita hipertensi dan pencapaian kualitas hidup optimal salah satunya dengan membantu meningkatkan kualitas tidur. Dengan mengedukasi penderita untuk menghindari konsumsi kopi dan rokok, membatasi aktivitas fisik, melakukan latihan fisik, dan terapi relaksasi.

Kata Kunci: Hipertensi, Kualitas Tidur, PSQI

\section{PENDAHULUAN}

Hipertensi merupakan penyebab utama penyakit kardiovaskular (Hartzell, Avis, Lozano, \& Feig, 2016), yang menyebabkan kematian nomor 1 di dunia.. Prevalensi Hipertensi di Indonesia sebanyak $25,8 \%$ atau 65.048.110 jiwa dan Jawa Barat memasuki peringkat ke-4 dengan prevalensi $29,4 \%$ atau sebanyak 13.612.359 jiwa (Riset Kesehatan Dasar [Riskesdas], 2013; Kemenkes RI, 2014). Hipertensi tidak menunjukan gejalagejala jelas sehingga penderita menganggap penyakit yang biasa (Utami, 2009). Gejala yang sering dirasakan penderita menurut Corwin (2001, dalam Nuraini, 2015) seperti obstructive sleep apnea syndrome (OSAS), restless legs syndrome, sakit kepala, pusing, sesak napas, nokturia yang dapat mengganggu tidur penderita (Black \& Hawks,
2014; Hanus, Amboni, da Rosa, Ceretta, \& Tuon, 2015).

Menurut Corteli (2004, dalam Lubis, 2013) gejala akibat penyakit hipertensi dapat mengganggu tidur yang berdampak terhadap kualitas tidur. Dengan demikian, adanya keluhan masalah tidur yang mempengaruhi kualitas tidur menjadi buruk pada penderita hipertensi akan memberikan dampak serius seperti mempengaruhi tekanan darah, memperparah perkembangan hipertensi, mengganggu pengendalian tekanan darah yang dapat menimbulkan resiko komplikasi stroke dan jantung (Zheng, Chen, Chen, Zhang, \& Wu, 2014). Penelitian lain menemukan bahwa penderita hipertensi dengan kualitas tidur yang buruk berdampak pada kualitas hidupnya (Xianlong, Yunshaang, \& Zumin, 2016). 
Agar dapat mengetahui seseorang melalui tahapan tidur normal dengan mendapatkan fase NREM (Non-Rapid Eye Movement) dan REM (Rapid Eye Movement) yang sesuai merujuk pada kualitas tidur (Kozier \& Berman, 2010). Kualitas tidur berkaitan dengan kejadian kardiovaskular (Lo, Woo, Martin, \& Wilson, 2018). Jika memiliki kualitas tidur yang baik maka dapat menurunkan resiko kejadian kardiovaskular (Wennman et al. 2014).

Beberapa penelitian sebelumnya yang dilakukan oleh Sagala (2011) di Puskesmas Medan Johor hasil menunjukan penderita hipertensi tidak dapat tidur dengan baik dan penelitian oleh Lubis (2013) di Puskesmas Medan Teladan hasil penelitian menunjukan yang sama bahwa penderita hipertensi tidak dapat tidur dengan baik. Kedua penelitian tersebut menggunakan kuesioner Sleep Quality Questionaires (SQQ) yang hanya meneliti dalam waktu 24 jam saja serta hanya terdiri dari dimensi latensi tidur, durasi tidur, kepulasan tidur, dan frekuensi terbangun pada malam hari.

Maka dari itu penting dilakukan penelitian terkait kualitas tidur pada penderita hipertensi yang dilakukan di Puskesmas Rancaekek karena berdasarkan studi pendahuluan Puskesmas Rancaekek termasuk kedalam 10 puskesmas peringkat terbesar yang memiliki kasus hipertensi se-Kabupaten Bandung sebanyak 2177 kasus dari bulan Januari November 2017 (Dinas Kesehatan [Dinkes], 2017). Selain itu, penyakit hipertensi di Puskesmas Rancaekek selalu memasuki peringkat 10 besar penyakit selama tahun 2017. Ditemukan juga penderita jantung dengan hipertensi sebanyak 13 orang, penderita stroke dengan hipertensi sebanyak 3 orang, dan penderita gagal ginjal dengan hipertensi hanya 1 orang. Berdasarkan wawancara dengan 5 penderita hipertensi, 3 orang diantaranya mengeluh sering merasakan sakit kepala dan merasakan kantuk pada siang hari (Pusat Kesehatan Masyarakat Rancaekek [Puskesmas Rancaekek], 2017). Hal tersebut merupakan tanda dan gejala dari kurang tidur yang akan mempengaruhi kualitas tidur. Menurut Potter dan Perry (2010) jika dicurigainya ada masalah tidur maka perlu diteliti lebih lanjut untuk menekan kejadian kardiovaskular yang diperkirakan akan semakin meningkat pada tahun 2030.

\section{BAHAN DAN METODE}

Jenis penelitian menggunakan deskriptif kuantitatif dengan metode cross sectional yaitu untuk mengetahui gambaran kualitas tidur penderita hipertensi di Puskesmas Rancaekek. Populasi pada penelitian ini yaitu penderita hipertensi rawat jalan di Puskesmas Rancaekek sebanyak 98 orang. Teknik sampel menggunakan NonProbability Sampling dengan Purposive Sampling. Dengan kriteria inklusi yaitu penderita hipertensi yang telah didiagnosis dokter minimal 1 bulan dan kriteria ekslusi yaitu penderita hipertensi yang mengkonsumsi obat jenis diuretik dan jenis beta-adregenic blockers. Sehingga sampel yang didapatkan sebanyak 79 orang.

Instrumen menggunakan kuesioner PSQI yang terdiri dari 7 dimensi yaitu kualitas tidur subjektif, latensi tidur, durasi tidur, efisiensi kebiasaan tidur, gangguan tidur, penggunaan obat tidur, dan gangguan aktivitas pada siang hari. Cara pengukuran pada kuesioner PSQI menggunakan skala Likert dimana setiap dimensi memiliki rentang skor 0-3 (0 tidak mengalami masalah, 1 mengalami masalah ringan, 2 mengalami masalah sedang, dan 3 mengalami masalah yang berat) sehingga total skor dari 7 dimensi pada rentang $0-21$. Jika jumlah total skor $\leq 5$ maka kualitas tidur baik dan jika total skor $>5$ maka kualitas tidur buruk (Buysse et al. 1989).

\section{HASIL}

Tabel 1 Karakteristik Demografi Pada Penderita Hipertensi di Puskesmas Rancaekek Kabupaten Bandung $(n=79)$

\begin{tabular}{lcc}
\hline Data Demografi & $\begin{array}{c}\text { Frekuensi } \\
\text { (f) }\end{array}$ & $\begin{array}{c}\text { Persentase } \\
(\%)\end{array}$ \\
\hline Usia: Mean & & \\
$(59,99 \pm 8,978)$ & & \\
$\quad$ (Min 33, Max 81) & 38 & 48,1 \\
$<60$ tahun & 41 & 51,9 \\
$\geq 60$ tahun & & \\
\hline Jenis Kelamin & 14 & 17,7 \\
Laki-laki & 65 & 82,3 \\
Perempuan & & \\
\hline Tekanan Darah Saat Ini: & 2 & 2,5 \\
120-129 / 80-84 mmHg & 7 & 8,9 \\
130-139 / 85-89 mmHg & 36 & 45,6 \\
140-159 / 90-99 mmHg & 26 & 32,9 \\
160-179 / 100-109 mmHg & 8 & 10,1 \\
$>180$ / 110 mmHg & & \\
\hline Lama Menderita & & \\
Hipertensi: & 15 & 19,0 \\
< 1 tahun & 15 & 19,0 \\
1-2 tahun & 11 & 13,9 \\
2-3 tahun & 2 & 45,6 \\
3-4 tahun & 36 & \\
>4 tahun & & \\
\hline Bekerja Shift: & &
\end{tabular}




\begin{tabular}{lcc}
\multicolumn{1}{c}{ Ya } & 0 & 0 \\
Tidak Dishift & 79 & 100 \\
\hline Zat Stimulasi: & & \\
Merokok & 8 & 10,1 \\
Ya & 71 & 89,9 \\
Tidak & & \\
\hline Kopi & 37 & 46,8 \\
Ya & 42 & 53,2 \\
Tidak & & \\
\hline Alkohol & 0 & 0 \\
Ya & 79 & 100 \\
Tidak & &
\end{tabular}

Berdasarkan Tabel 1 karakteristik demografi pada penderita hipertensi di Puskesmas Rancaekek didapatkan hasil bahwa lebih dari setengah responden yaitu usia lanjut $\geq 60$ tahun $(51,9 \%)$, yang sebagian besar berjenis kelamin perempuan (82,3\%), kurang dari setengah responden memiliki tekanan darah pada derajat satu (140-159/90$99 \mathrm{mmHg}$ ) (45,6\%) dan lama menderita hipertensi $>4$ tahun (45,6\%), yang mayoritas responden tidak bekerja shift (100\%), sebagian besar responden tidak merokok $(89,9 \%)$, dan sebagian responden tidak mengkonsumsi kopi $(53,2 \%)$, serta mayoritas responden tidak mengkonsumsi alkohol $(100 \%)$.

Tabel 2 Hasil Kualitas Tidur pada Penderita Hipertensi di Puskesmas Rancaekek Kabupaten Bandung $(n=79)$

\begin{tabular}{lcc}
\hline Kualitas Tidur & Frekuensi $(\boldsymbol{f})$ & Persentase $(\%)$ \\
\hline Baik & 4 & 5,1 \\
\hline Buruk & 75 & 94,9 \\
\hline Total & 79 & 100 \\
\hline
\end{tabular}

Berdasarkan Tabel 2 hasil kualitas tidur pada penderita hipertensi di Puskesmas Rancaekek menunjukan bahwa mayoritas responden memiliki kualitas tidur buruk sebanyak $94,9 \%$.

Tabel 3. Dimensi Kualitas Tidur pada Penderita Hipertensi di Puskesmas Rancaekek Kabupaten Bandung $(n=79)$

\begin{tabular}{|c|c|c|}
\hline Kualitas Tidur & Frekuensi (f) & $\begin{array}{c}\text { Persentase } \\
(\%)\end{array}$ \\
\hline Kualitas Tidur & & \\
\hline $\begin{array}{l}\text { Subjektif } \\
\text { Sangat Baik }\end{array}$ & 5 & 6,3 \\
\hline Cukup Baik & 41 & 51,9 \\
\hline Cukup Buruk & 24 & 30,4 \\
\hline Sangat Buruk & 9 & 11,4 \\
\hline Latensi Tidur & & \\
\hline Skor 0 & 14 & 17,7 \\
\hline Skor 1 & 19 & 24,1 \\
\hline Skor 2 & 12 & 15,2 \\
\hline Skor 3 & 34 & 43,0 \\
\hline $\begin{array}{c}\text { Durasi Tidur } \\
>7 \text { jam }\end{array}$ & 1 & 1,3 \\
\hline
\end{tabular}

\begin{tabular}{lcc}
\hline $6-7$ jam & 6 & 7,6 \\
\hline $5-6$ jam & 19 & 24,1 \\
\hline$<5$ jam & 53 & 67,1 \\
\hline $\begin{array}{l}\text { Efisiensi Kebiasaan } \\
\text { Tidur } \\
>85 \%\end{array}$ & 21 & 26,5 \\
\hline $84-75 \%$ & 12 & 15,2 \\
\hline $74-65 \%$ & 10 & 12,7 \\
\hline$<65 \%$ & 36 & 45,6 \\
\hline $\begin{array}{l}\text { Gangguan Tidur } \\
\text { Skor 1 }\end{array}$ & 25 & 31,6 \\
\hline Skor 2 & 51 & 64,6 \\
\hline Skor 3 & 3 & 3,8 \\
\hline $\begin{array}{l}\text { Penggunaan Obat } \\
\text { Tidur } \\
\text { Ya }\end{array}$ & 0 & 0 \\
\hline $\begin{array}{l}\text { Tidak pernah } \\
\text { selama sebulan }\end{array}$ & 79 & 100 \\
\hline $\begin{array}{l}\text { Gangguan aktivitas } \\
\text { pada siang hari } \\
\text { Skor 0 }\end{array}$ & 16 & 20,3 \\
\hline Skor 1 & & \\
\hline Skor 2 & 22 & 27,8 \\
\hline Skor 3 & 35 & 4,3 \\
\hline
\end{tabular}

Berdasarkan Tabel 4.3 diatas menunjukan lebih dari setengah responden pada dimensi kualitas tidur subjektif penderita hipertensi merasa cukup baik terhadap tidurnya sebanyak $51,9 \%$, dimensi latensi tidur menunjukan kurang dari setengah responden memiliki skor 3 sebanyak $43,0 \%$ item pertanyaan tidak dapat tertidur dalam waktu 30 menit yang dirasakan $\geq 3$ kali dalam seminggu sebanyak $44,3 \%$, pada dimensi durasi tidur lebih dari setengah responden memiliki durasi tidur malam $<5$ jam sebanyak $67,1 \%$, kurang dari setengah responden pada dimensi efisiensi kebiasaan tidur yaitu memiliki efisiensi kebiasaan tidur $<65 \%$ sebanyak $45,6 \%$, lalu pada dimensi gangguan tidur lebih dari setengah responden memiliki skor 2 sebanyak $64,6 \%$ item pertanyaan gangguan tidur terbangun ditengah malam atau pagi-pagi sekali yang dialami $\geq 3$ kali dalam seminggu sebanyak $81 \%$ dan terbangun karena ingin ke toilet yang dialami $\geq 3$ kali dalam seminggu sebanyak $77,2 \%$, sedangkan mayoritas responden pada dimensi penggunaan obat tidur sebanyak $100 \%$ tidak pernah mengkonsumsi obat selama sebulan terakhir, dan pada dimensi gangguan aktivitas pada siang hari kurang dari setengah responden memiliki skor 2 sebanyak $44,3 \%$.

\section{PEMBAHASAN}

Usia yang menunjukan sebanyak 41 orang $(51,9 \%)$ usianya $\geq 60$ tahun. Lansia beresiko mudah terkena penyakit, sehingga pada penelitian ini penderita hipertensi lebih banyak ditemukan pada usia $\geq 60$ tahun. 
Hipertensi terjadi karena dinding pembuluh darah mengalami kekakuan maka beban kerja jantung semakin keras sehingga terjadi tekanan darah tinggi (Liu \& Zheng, 2017). Hal ini didukung beberapa penelitian lain bahwa hipertensi sering ditemukan yang usianya $\geq 60$ tahun (Lionakis et al. 2012; Setyaningsih et al. 2014).

Sebanyak 65 orang $(82,3 \%)$ berjenis kelamin perempuan. Perempuan lebih beresiko terkena hipertensi dibandingkan lakilaki. Semakin bertambahnya usia pada perempuan maka mengalami penurunan hormon estrogen yang dimana fungsi hormon estrogen untuk meningkatkan High Density Lipoprotein $(\mathrm{HDL})$ untuk mencegah penebalan pembuluh darah sehingga semakin tua hormon tersebut tidak bekerja yang beresiko terjadi arterosklerosis lebih tinggi yang dapat meningkatkan tekanan darah (Kartikasari, 2012). Penelitian lain juga menemukan bahwa hipertensi sering ditemukan pada perempuan dibandingkan laki-laki (Lionakis et al. 2012).

Hasil menunjukan sebanyak 36 orang $(45,6 \%)$ responden mengidap hipertensi derajat 1. Hal tersebut diasumsikan bahwa beberapa responden teratur dalam melakukan pengobatan salah satunya mengkonsumsi obat antihipertensi secara teratur sehingga mayoritas tekanan darah responden berada pada derajat 1. Hal ini didukung oleh penelitian Hairunnisa (2014) yang menunjukan adanya hubungan tingkat kepatuhan minum obat antihipertensi dengan tekanan darah yang terkontrol.

Seluruh responden 79 orang (100\%) tidak bekerja shift. Meskipun responden tidak bekerja shift akan tetapi pada penelitian ini didominasi oleh perempuan dan salah satu gejala penderita hipertensi yang dirasakan yaitu mudah lelah. Hal ini didukung oleh penelitian Sari (2017) yang menemukan lansia hipertensi di Desa Rancaekek mudah lelah.

Penelitian ini menunjukan bahwa kualitas tidur pada penderita hipertensi di Puskesmas Rancaekek mayoritas buruk sebanyak 75 orang $(94,9 \%)$ dan hanya 4 orang $(5,1 \%)$ yang memiliki kualitas tidur baik. Kondisi tersebut menunjukan bahwa responden lebih banyak memiliki kualitas tidur buruk dibandingkan kualitas tidur baik dikarenakan faktor usia, jenis kelamin, derajat hipertensi dan lama menderita hipertensi, serta zat stimulasi seperti merokok dan konsumsi kafein. Kualitas tidur baik hal ini terjadi karena lama menderita hipertensi $\leq 2$ tahun sehingga gejala kurang dirasakan maka tidak mengalami gangguan tidur. Menurut
Harfiantoko dan Kurnia (2013) kualitas tidur baik dimiliki oleh penderita hipertensi dengan lama menderita hipertensi 1-2 tahun. Selain itu, responden yang usianya $\geq 60$ tahun memiliki kualitas tidur baik karena responden telah mampu beradaptasi terhadap perubahan tidur sehingga tetap memiliki siklus tidur normal (Potter \& Perry, 2010), serta responden tidak mengkonsumsi kopi dan tidak merokok yang dapat mempengaruhi kualitas tidur.

Hasil yang menunjukan kualitas tidur buruk sejalan dengan penelitian Xianlong et al. (2016) dimana penderita hipertensi memiliki kualitas tidur buruk sebanyak $67,3 \%$. Selain itu, penelitian Hanus et al. (2015) menunjukan bahwa kualitas tidur pada penderita hipertensi buruk sebanyak 156 orang dari 280 orang.

Penderita hipertensi memiliki kecemasan berlebih sehingga mengalami gangguan emosi dan akan mengalami gangguan tidur sehingga mempengaruhi kualitas tidur (Hanus et al. 2015), gejala kecemasan yang dirasakan akan mengganggu tidurnya seperti jantung berdebar-debar, gemetar, gelisah (Harfiantoko \& Kurnia, 2013; Wu, Chien, \& Lin, 2014). Kecemasan tersebut dapat diperparah oleh usia dan jenis kelamin dikarenakan penurunan hormon estrogen yang mempengaruhi psikologis sehingga berpengaruh terhadap kualitas tidur (Kartikasari, 2012). Zat nikotin dan kafein pun mempengaruhi kualitas tidur (Ogeil \& Phillips, 2015). Latihan fisik yang rendah pada penderita hipertensi juga mempengaruhi kualitas tidur (Kline, 2014). Selain itu, kualitas tidur dipengaruhi oleh lama menderita hipertensi (Harfiantoko \& Kurnia, 2013).

Dimensi kualitas tidur subjektif sebanyak 41 orang $(51,9 \%)$ mengatakan bahwa tidurnya cukup baik. Responden kurang mengetahui pentingnya tidur, ketika responden mengatakan jika malam tidur nyenyak hanya beberapa jam dalam satu bulan terakhir karena mengalami gangguan tidur dan masih mengatakan tidur dalam satu bulan terakhirnya cukup baik karena sudah merasakan usianya cukup tua sehingga tidak mempermasalahkan. Hal ini didukung oleh Khasanah dan Hidayati (2012) lansia menilai kualitas tidurnya cukup baik karena lansia mampu mentoleransi perubahan tidur sebagai proses penuaan dan tidak menganggap bahwa masalah tidur berbahaya terhadap kesehatannya. 
Latensi tidur dimana item pertanyaan jumlah waktu yang dibutuhkan untuk memulai tertidur sebanyak 25 orang $(31,6 \%)<15$ menit dan item pertanyaan tidak dapat tertidur dalam waktu 30 menit sebanyak 53 orang $(44,3 \%)$ yang terjadi $\geq 3$ kali dalam seminggu. Hal tersebut terjadi karena responden lebih banyak pada usia lanjut, dimana usia lanjut yang mampu beradaptasi terkait perubahanperubahan fisiologis yang terjadi akan memiliki siklus tidur seperti orang normal yang akan menghabiskan waktu 10-30 menit (Potter \& Perry, 2010). Sedangkan pada item tidak dapat tertidur dalam 30 menit yang terjadi $\geq 3$ kali dalam seminggu terjadi dikarenakan gejala akibat penyakit hipertensi membuat sulit untuk tertidur. Hal ini seiring dengan penelitian lain bahwa penderita hipertensi membutuhkan waktu untuk dapat tertidur lebih lama yaitu $>30$ menit sebanyak $35 \%$ dan salah satu faktor gangguan tidur yang mengakibatkan penderita hipertensi tidak dapat tidur dengan baik karena pusing atau sakit kepala sebanyak $81 \%$ (Lubis, 2013).

Diikuti dimensi durasi tidur yang hanya $<5$ jam sebanyak 53 orang $(67,1 \%)$. Responden mengatakan nyenyak tidur hanya beberapa jam dikarenakan mudah dan seringnya terbangun pada malam hari. Sejalan dengan penelitian Hanus et al. (2015) bahwa penderita hipertensi memiliki durasi tidur yang pendek.

Lalu rasio dimensi efisiensi kebiasaan tidur yaitu $<65 \%$ sebanyak 36 orang $(45,6 \%)$ yang artinya responden tidak dapat tidur dengan efisien yaitu lebih banyak menghabiskan waktu diatas tempat tidur namun tidak tertidur. Responden mengatakan sering mengalami gangguan tidur yang membuat responden terbangun dari tidurnya dan jika sudah terbangun sulit untuk tertidur kembali bahkan tidak tertidur kembali hingga pagi. Mansoor (2002) mengatakan bahwa penderita hipertensi lebih banyak menghabiskan waktu ditempat tidur.

Sebanyak 51 orang $(64,6 \%)$ mengalami gangguan tidur karena terbangun ditengah malam atau pagi-pagi sekali sebanyak 64 orang $(81,0 \%)$ selama $\geq 3$ kali dalam seminggu. Selain itu responden sering terbangun karena ingin ke toilet sebanyak 61 orang $(77,2 \%)$ selama $\geq 3$ kali dalam seminggu. Responden memiliki gangguan tidur yaitu seringnya terbangun malam atau pagi sekali karena nokturia. Lubis (2013) menyebutkan bahwa penderita hipertensi memiliki gangguan tidur sebanyak $64 \%$ karena nokturia.

Dimensi penggunaan obat tidur pada penderita hipertensi seluruhnya 79 orang (100\%) tidak mengkonsumsi obat tidur dalam satu bulan terakhir. Hal tersebut karena obat yang telah dikonsumsi oleh responden selain obat antihipertensi yaitu golongan obat Antihistamin dan Reseptor Antihistamin 2, golongan ekspektoran. Golongan obat-obatan tersebut memiliki efek samping mengantuk yang dapat membantu tidur (Gunawijaya, 2011; Putra, 2016).

Serta pada dimensi gangguan aktivitas pada siang hari sebanyak 35 orang $(44,3 \%)$ yang mempengaruhi skor menjadi tinggi sehingga berkontribusi terhadap kualitas tidur menjadi buruk. Gangguan aktivitas pada siang hari diawali dari kurang istirahat pada malam hari. Hal ini didukung oleh penelitian Sari (2017) menunjukan lansia hipertensi di Desa Rancaekek memiliki kualitas hidup buruk $54,9 \%$ yang salah satunya kurang memiliki kepuasaan terhadap tidur.

\section{KESIMPULAN DAN SARAN}

Kualitas tidur pada penderita hipertensi di Puskesmas Rancaekek dengan menggunakan kuesioner PSQI yang mengevaluasi tidur selama satu bulan terakhir dengan pengambilan data dalam satu waktu didapatkan hasil bahwa yang memiliki kualitas tidur buruk sebanyak 94,9\% dan hanya 5,1\% yang memiliki kualitas tidur baik. Kualitas tidur subjektif 51,9\% mengatakan cukup baik, latensi tidur 43,0\% dimana penderita hipertensi pada item tidak dapat tertidur dalam waktu 30 menit dengan $\geq 3$ kali dalam seminggu, sebanyak $67,1 \%$ memiliki durasi tidur $<5$ jam, 45,6\% memiliki efisiensi kebiasaan tidur $<65 \%$, gangguan tidur sebanyak $64,6 \%$ yang mengalami terbangun di tengah malam atau pagi-pagi sekali, terbangun karena ingin ke toilet dengan masing-masing $\geq 3$ kali dalam seminggu, $100 \%$ tidak menggunakan obat tidur, dan mengalami gangguan aktivitas pada siang hari $44,3 \%$.

\section{DAFTAR PUSTAKA}

Black \& Hawks. (2014). Keperawatan Medikal Bedah: Manajemen Klinis Untuk Hasil yang Diharapkan. In 2 (8th ed.). Singapore: Elsevier.

Buysse, D. J., Reynolds, C. F., Monk, T. H., Berman, S. R., Kupfer, D. J., III, C. F. R., ... Kupfer, D. J. (1989). The Pittsburgh Sleep Quality Index: a new instrument 
for psychiatric practice and research. Psychiatry Research, 28(2), 193-213. https://doi.org/10.1016/01651781(89)90047-4

Dinkes. (2017). Laporan PTM Puskesmas. Kabupaten Bandung.

Gunawijaya, F. . (2011). Manfaat Penggunaan Antihistamin Generasi Ketiga. Kedokteran Trisakti, 2, 123-129. Retrieved from http://www. univmed.org/wp-content/uploads/2011/ 02/anthistamin.pdf

Hairunnisa. (2014). Hubungan Tingkat Kepatuhan minum Obat dan Diet dengan Tekanan Darah Terkontrol Pada penderita Hipertensi lansia di wilayah Kerja Puskesmas Perumnas I Kecamatan Pontianak Barat. Fakultas Kedokteran, Universitas Tanjungpura, Pontianak, 25. https://doi.org/10.1017/ CBO9781107415324.004

Hanus, J. S., Amboni, G., da Rosa, M. I., Ceretta, L. B., \& Tuon, L. (2015). The quality and characteristics of sleep of hypertensive patients. Revista Da Escola de Enfermagem, 49(4), 594-599. https://doi.org/10.1590/S0080623420150000400009

Harfiantoko, M. N., \& Kurnia, E. (2013). Derajat Hipertensi (Menurut Who) Mempengaruhi Kualitas Tidur dan Stress Psikososial Mirza Nursyamsu Harfiantoko, Erlin Kurnia. Jurnal STIKES, Vol. 6 No.

Hartzell, K., Avis, K., Lozano, D., \& Feig, D. (2016). Obstructive sleep apnea and periodic limb movement disorder in a population of children with hypertension and/or nocturnal nondipping blood pressures. Journal of the American Society of Hypertension, 10(2), 101-107. https://doi.org/10.1016/j.jash.2015.11.01 0

Kartikasari, A. N. (2012). Faktor Risiko Hipertensi pada Masyarakat di Desa Kabongan Kidul, Kabupaten Rembang, $1-26$.

Kemenkes RI. (2014). Pusdatin Hipertensi. Infodatin, (Hipertensi), 1-7. https://doi.org/10.1177/10901981740020 0403

Khasanah, K., \& Hidayati, W. (2012). Kualitas Tidur Lansia Balai Rehabilitasi Sosial “ mandiri " Semarang. Jurnal Nursing Studies, 1(1), 189-196. Retrieved from http://ejournals1.undip.ac.id/index.php/jnursing

Kline, C. E. (2014). The Bidirectional
Relationship Between Exercise and Sleep: Implications for Exercise Adherence and Sleep Improvement. American Journal of Lifestyle Medicine, $8(6)$, 375-379. https://doi.org/10.1177/15598276145444 37

Kozier \& Berman. (2010). Buku Ajar Fundamental Keperawatan: Konsep, Proses, \& Praktik (7th ed.). Jakarta: EGC.

Lionakis, N., Mendrinos, D., Sanidas, E., Favatas, G., \& Georgopoulou, M. (2012). Hypertension in the elderly. World Journal of Cardiology, 4(5), 135. https://doi.org/10.4330/wjc.v4.i5.135

Liu, P., \& Zheng, J. G. (2017). Blood pressure targets in the hypertensive elderly. Chinese Medical Journal, 130(16), 1968-1972.

https://doi.org/10.4103/03666999.211885

Lo, K., Woo, B., Martin, B. N., \& Wilson, W. (2018). Subjective sleep quality, blood pressure, and hypertension: a meta- analysis, (December 2017), 592-605. https://doi.org/10.1111/jch. 13220

Lubis, D. P. (2013). Kualitas tidur dan faktorfaktor gangguan tidur pada penderita hipertensi di Wilayah Kerja Puskesmas Medan Teladan.

Mansoor, G. A. (2002). Sleep actigraphy in hypertensive patients with the "nondipper" blood pressure profile. Journal of Human Hypertension, 16(4), 237-242. https://doi.org/10.1038/sj/jhh/1001383

Nuraini, B. (2015). Risk factors of hypertension. J Majority, 4(5), 10-19.

Ogeil, R. P., \& Phillips, J. G. (2015). Commonly used stimulants: Sleep problems, dependence and psychological distress. Drug and Alcohol Dependence, 153, 145-151. https://doi.org/10.1016/j.drugalcdep.2015 .05 .036

Potter \& Perry. (2010). Fundamental Keperawatan. In 3 (7th ed.). Singapore: Elsevier.

Puskesmas Rancaekek. (2017). Laporan Tahunan. Bandung.

Putra, F. S. (2016). Pengaruh pemberian ranitidin terhadap gambara histopatologi gaster tikus wistar pada pemberian metanol dosis bertingkat, 5(4), 8-9.

Riskesdas. (2013). Badan Penelitian dan Pengembangan Kesehatan. Laporan Nasional 2013, 1-384. https://doi.org/1 Desember 2013 
Sagala, V. P. (2011). Kualitas Tidur dan Faktor-Faktor Gangguan Tidur pada Penderita Hipertensi di Wilayah Kerja Puskesmas Medan Johor.

Sari, W. Y. (2017). Gambaran kualitas lansia dengan hipertensi di desa rancaekek wetan kabupaten bandung dan kelurahan maleber kota bandung.

Setyaningsih, R. D., Dewi, P., \& Suandika, M. (2014). Studi Prevalensi dan Kajian Faktor Risiko Hipertensi pada Lansia di Desa Tambaksari Banyumas.

Utami, P. (2009). Solusi Sehat Mengatasi Hipertensi (1st ed.). Jakarta: Agromedia Pustaka.

Wennman, H., Kronholm, E., Partonen, T., Tolvanen, A., Peltonen, M., \& Vasankari, T. (2014). Physical activity and sleep profiles in Finnish men and women. BMC Public Health, 14(1), 1-10. https://doi.org/10.1186/1471-2458-14-82

Wu, E.-L., Chien, I.-C., \& Lin, C.-H. (2014). Increased risk of hypertension in patients with anxiety disorders: A populationbased study. Journal of Psychosomatic Research, 77(6), 522-527. https://doi.org/10.1016/j.jpsychores.2014 .10 .006

Xianlong X, Yunshaang R, \& Zumin S. (2016). Hypertension Impact on Health-Related Quality of Life: A Cross-Sectional Survey among Middle-Aged Adults in Chongping China'. Internation Jounrnal of Hypertension, 2016, 1-7.
Zheng, L.-W., Chen, Y., Chen, F., Zhang, P., \& Wu, L.-F. (2014). Effect of acupressure on blood pressure and sleep quality of middle-aged and elderly patients with hypertension. International Journal of Nursing Sciences, 1(4), 334338.

https://doi.org/10.1016/j.ijnss.2014.10.01 2 